\title{
Development of a Prototype of Guidance System for Rice-transplanter
}

\author{
Fang-ming Zhang ${ }^{1,2}$, Beom-Soo Shin ${ }^{3}$, Xi-ming Feng ${ }^{2}$, Yuan $\mathrm{Li}^{2}$, Ru-jiang Shou ${ }^{4}$ \\ ${ }^{1}$ Ningbo Institute of Technology, Zhejiang University, Ningbo, Zhejiang, China \\ ${ }^{2}$ Ningbo Yinzhou MicroAgriculture Technology Ltd., Ningbo, Zhejiang, China \\ ${ }^{3}$ Kangwon National University, Chuncheon, Korea \\ ${ }^{4}$ Ningbo Agricultural Machinery Popularizing Center, Ningbo, Zhejiang, China
}

Received: August $28^{\text {th }}, 2013$; Revised: September $16^{\text {th }}, 2013$; Accepted: October $5^{\text {th }}, 2013$

\section{Abstract}

Purpose: It is not easy to drive a rice-transplanter avoiding underlapped or overlapped transplanting in paddy fields. An automated guidance system for the riding-type rice-transplanter would be necessary to operate the rice-transplanter autonomously or to assist the beginning drivers as a driving aid. Methods: A prototype of guidance system was composed of embedded computers, RTK-GPS, and a power-steering mechanism. Two Kalman filters were adopted to overcome sparse positioning data $(1 \mathrm{~Hz})$ from the RTK-GPS. A global Kalman filter estimated the posture of rice-transplanter every one second, and a local Kalman filter calculated the posture from every new estimation of the global Kalman filter with an interval of $200 \mathrm{~ms}$. A PID controller was applied to the row-following mode control. A control method of U-turning mode was developed as well. A stepping motor with a reduction gear set was used to rotate the shaft of steering wheel. Results: Test trials for U-turning and row-following modes were done in a paddy field after some parameters have been tuned at the ground speed range of $0.3 \sim 1.2 \mathrm{~m} / \mathrm{s}$. The minimum RMS error of offset was $3.13 \mathrm{~cm}$ at the ground speed of $0.3 \mathrm{~m} / \mathrm{s}$ while the maximum RMS error was $13.01 \mathrm{~cm}$ at $1.2 \mathrm{~m} / \mathrm{s}$. The offset RMS error tended to increase as the ground speed increased. The target point distance, $\mathrm{L}_{\mathrm{T}}$ also affected the system performance and PID controller parameters should be adjusted on different ground speeds. Conclusions: A target angle-based PID controller plus stationary steering angle controller made it possible for the rice-transplanter to steer autonomously by following a reference line accurately and even on U-turning mode. However, as condition in paddy fields is very complicated, the system should control the ground speed that prevents it from deviating too much due to ditch and slope.

Keywords: Guidance system, Positioning system, Rice-transplanter, Row-following, U-turning

\section{Introduction}

Maintaining planting or sowing space precisely is one of the major factors to maximize the agricultural productivity in a field. In order to avoid overlap or underlap between the operation paths, the machine should be driven along the virtual path generated from the previous pass of operation. This must be a very difficult job for unskillful farmers even in irregular and swampy soil conditions.

\footnotetext{
*Comesponding author: Beom-Soo Shin

Tel: +82-33-250-6493; Fax: +82-33-259-5561

E-mail: bshin@kangwon.ac.kr
}

Therefore, the machine needs to be developed in a way such a non-expert driver can operate it with ease under any working conditions. An automatic guidance system can be used for the transplanter or the seeder as a driving aid and the basis for future field robot.

To achieve the goal, first of all, the positioning of the machine should be determined accurately and a control algorithm for the steering control needs to be developed. Multi-sensor based sensor fusion methods have been adopted in most previous systems. Noguchi et al. (2001) used RTK-GPS, FOG, and IMU as guidance sensors, where a sensor fusion algorithm was used to identify FOG bias 
and compensate for location error in real-time. Subramanian and Burks (2006) used a fuzzy Kalman filter to fuse the information from machine vision, laser radar, IMU and speed sensor. Mizushima et al. (2011) developed an attitude sensor, composed of three vibratory gyroscopes and two inclinometers, and a sensor fusion algorithm to estimate heading angle by integrating a GPS, and tilt angles (roll and pitch) by least-squares method. Guo et al. (2002) developed a position estimation system, consisted of a six-axis IMU and low-cost GPS. Zhang et al. (2006) have fused machine vision and odometer, and later Zhang et al. (2012) integrated a low-cost GPS, odometer and gyroscope.

In the aspect of control methods, PID controller is known to be very effective method to steer a vehicle in a row-following work mode, such as Luo's PID controller (Luo et al. (2009)), Hu's PD controller (Hu et al. (2009)), and Chen's PD controller (Chen et al. (2006)). Tillett et al. (1998) integrated offset and heading angle with corresponding coefficient: $d=K_{p} y+K_{d} \theta$, which is a $P$ controller only. However, agricultural machines have to travel along some curved path. Kise et al. (2002) applied a linear optimal regulator for curved paths guidance. Yekutieli and Pegna (2002) used a two-stage ON/OFF control to guide a crawler tractor automatically in a vineyard, with the vine trees used as a guidance line. Shin et al. (2002) used a fuzzy logic controller to steer a track type orchard sprayer by tracking the overhead guidance rail. Han et al. (2013) developed a path generation and tracking algorithm for a Korean auto-guidance tillage tractor, where RTK-GPS transmitting data at $10 \mathrm{~Hz}$ with a baud rate of 115,200 bps was used. John Deere's commercialized guidance system provides 2 9 inch pass-to-pass accuracy depending on GPS receiver.

Although it was true that RTK-GPS with additional sensors provided highly accurate position data in most research works, it was also true that RTK-GPS was too expensive to be widely used in low cost agricultural machines. In this research, a less expensive RTK-GPS at the range of USD 3,000.00 with $1 \mathrm{~Hz}$ update rate was used for positioning system. And two Kalman filters were then introduced into this system, which resulted in increasing the update rate of positioning data up to $5 \mathrm{~Hz}$.

The objectives of this research were: 1 ) to develop the control algorithm with a prototype of guidance system and 2) to evaluate the system performance in paddy fields.

\section{Materials and Methods}

\section{Platform}

A guidance system was constructed on a rice-transplanter (PZ60, ISEKI, Japan) as shown in figure 1, which was composed of three parts: guidance sensors, embedded computers, and a power-steering mechanism. The guidance sensors consisted of one RTK-GPS receiver (S82E, South surveying \& mapping Inc, China) and one strapdown attitude sensor (RAH150, Right M\&C Inc, China). A potentiometer (N35, Copal-Electronics, Japan) was installed beside one front-wheel to measure the turning angle of the vehicle. The RTK-GPS was mounted $2.5 \mathrm{~m}$ above ground level and its receiver transmitted data at $1 \mathrm{~Hz}$ with the baud rate of 19,200 bps. The embedded computer system consisted of one embedded central computer (ECC) (iACC9161, Microagriculture Inc., China) and three electric circuit units (ECU) (iACU248, Microagriculture Inc., China). The $1^{\text {st }}$ ECU transferred current position data from the GPS receiver to the ECC. The $2{ }^{\text {nd }}$ ECU was used to acquire the heading, roll and pitch angles from the attitude sensor and to send them to the ECC. Not only the $3^{\text {rd }}$ ECU governed a step motor to drive the steering wheel, but also measured the turning angle of the frontwheel. The ECC and all ECUs are connected through CAN bus.

All sensors were synchronized by signal of the RTK-GPS, that is, when the ECU1 received the '\$GPGGA' frame, it extracted latitude and longitude and then sent them to the ECC through the CAN bus, all other ECUs then started to read sensors. The ECC processed all sensor data, and then they were sent to the Kalman filters.

\section{Positioning method}

Due to sparse data flow $(1 \mathrm{~Hz})$ from the RTK-GPS, two Kalman filters, so called global filter and local filter, were used to estimate positions. The global filter ran every one second just after the system received data of all sensors. Position and translational velocity transformed from the RTK-GPS, angular velocity and heading angle extracted from the attitude sensor, were observed quantities for this Kalman filter. Interpolation between satellite positions was carried out by the local Kalman filter, which was restarted after every new estimation of the global Kalman filter and run with an interval of $200 \mathrm{~ms}$. Translational velocity from history data of RTK-GPS, angular velocity and heading angle were observed quantities. The 
transplanter was modeled as a three-tyre vehicle as shown in figure 2. Based on kinematics analysis, an identical position-velocity (PV) model was set up both for these two filters, where $\mathrm{x}$ - and $\mathrm{y}$-position, heading angle, angular velocity (turning speed), and translational velocity of the vehicle are state variables as following.

$$
X_{k}=\left[x_{k}, y_{k}, \psi_{k}, \omega_{k}, v_{k}\right]
$$

where,

$x_{k}$ and $y_{k}$; local coordinates to be estimated,

$\Psi_{k}$; heading angle to be estimated,

$\omega_{k}$; angular velocity on Z-axis of the vehicle, and

$v_{k}$; translational velocity to be estimated.

Based on the PV model in figure 2(b), the state transition matrix was:

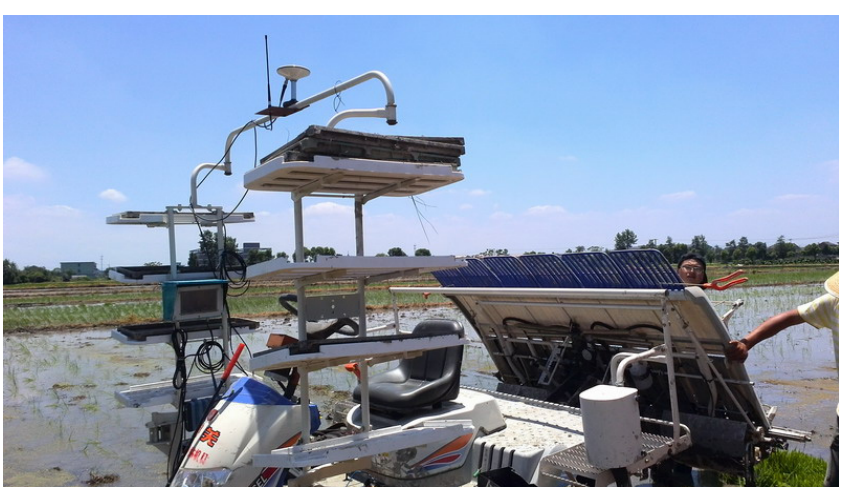

Figure 1. Platform rice-transplanter.

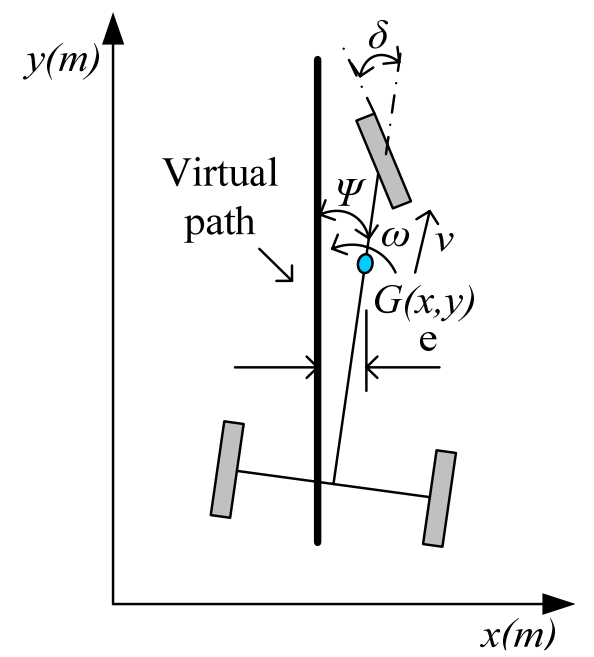

(a)

$$
\phi_{k}=\left[\begin{array}{ccccc}
1 & 0 & 0 & T \sin \psi_{k} & 0 \\
0 & 1 & 0 & T \cos \psi_{k} & 0 \\
0 & 0 & 1 & T & 0 \\
0 & 0 & 0 & 1 & 0 \\
0 & 0 & 0 & 0 & 1
\end{array}\right]
$$

where, $T$ is a time parameter. It was set to 1 in the global filter, and 0.2 in the local filter as it updated data every $200 \mathrm{~ms}$.

Measurement vectors were different in these two filters because the local Kalman filter could not get observation of $x$ and $y$. The measurement vectors and the observation matrix for the global Kalman filter were:

$$
\begin{aligned}
Z_{k} & =\left[x_{G P S}, y_{G P S}, \psi_{g y r o}, \omega_{g y r o}, v_{G P S}\right]^{T} \\
H_{k} & =\left[\begin{array}{lllll}
1 & 0 & 0 & 0 & 0 \\
0 & 1 & 0 & 0 & 0 \\
0 & 0 & 1 & 0 & 0 \\
0 & 0 & 0 & 1 & 0 \\
0 & 0 & 0 & 0 & 1
\end{array}\right]
\end{aligned}
$$

The measurement vectors and the observation matrix for the local Kalman filter were:

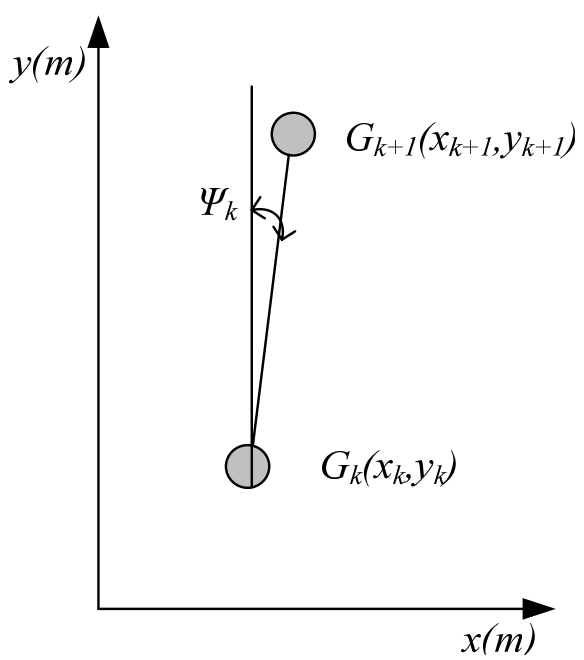

(b)

Figure 2. (a) Model of three-tyre vehicle, ' $G$ ' represents the position of GPS. The virtual path is parallel to $y$-axis as the coordinate system is built on a local paddy field. Position, $x$ and $y$, heading angle, $\Psi$, angular velocity, $\omega$, and translational velocity, $v$, are state variables of this model. Offset, e, and steering angle, $\delta$, are used for steering control. (b) relationship of positions between time $k$ to $k+1$ in the PV model. 


$$
\begin{aligned}
Z_{k}= & {\left[\psi_{\text {gyro }}, \omega_{\text {gyro }}, v_{G P S}\right]^{T} } \\
H_{k} & =\left[\begin{array}{lllll}
0 & 0 & 1 & 0 & 0 \\
0 & 0 & 0 & 1 & 0 \\
0 & 0 & 0 & 0 & 1
\end{array}\right]
\end{aligned}
$$

Supposing the speed of the vehicle was stable in every one second, the observed ground speed, $v_{G P S}$ was equal to the last measurement on GPS.

If the $1^{\text {st }}$ point in every experiment was set as the origin point, and the latitude direction as $\mathrm{x}$-axis and the longitude direction as $y$-axis, the position of rice-transplanter could be described in the meter measurement like used in Zhang et al. (2012). However, the offset defined as the distance from the current position to the guidance line was little complicated to be calculated. A field coordinate system (FCS) was set up by rotating the Latitude-Longitude coordinate system so that the line running from SW corner to SE corner in a paddy field became the $\mathrm{x}$-axis and the line from SW corner to NW corner became the y-axis. Then virtual paths were all parallel to the $\mathrm{x}$ - or $\mathrm{y}$-axis of the FCS.

As the GPS located on 2.5 meters high above the ground, position error caused by inclination of the vehicle was corrected by using Noguchi's method (Noguchi et al., 2001), too.

\section{Control method}

Offset and heading angle of the vehicle considered as two key parameters in an automated guidance system could be integrated into a target angle, $\theta$, which is an angle

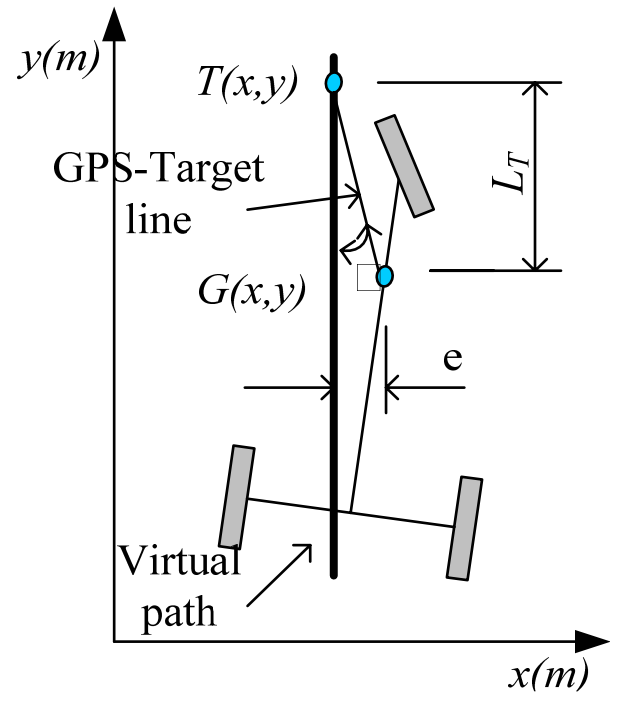

Figure 3. Target point $(\mathrm{T})$ and target angle $(\theta)$. between the virtual path and GPS-target line as shown in figure 3.

A target point was located on the virtual path with distance of ' $L_{T}$ ' away from the GPS position, and its coordinate was outputted from the positioning system. Relationship between the target angle and offset is:

$$
\tan (\theta)=\frac{e}{L_{T}}
$$

A PID controller with stationary steering angle for the steering wheel was introduced into this control system for better performance. After the position of GPS point was estimated, the coordinate of target point was calculated, and then the target angle was generated. Steering angle was calculated by the PID algorithm in the range of less than $5 \mathrm{~cm}$ in the offset value, or a fixed steering angle could replace the PID output if the offset value exceeded the limit. Steering angle was finally sent to the ECU3 to control the electro-steering wheel.

\section{Results and Discussion}

This prototype system was tested both on an asphalted surface and several paddy fields. For the preliminary test, the rice-transplanter moved autonomously with a U-turning mode on the asphalted surface. It moved along a reference line for 10 meters with speed of $0.3 \mathrm{~m} / \mathrm{s}$, and then made a U-turn automatically, and moved back along the $2^{\text {nd }}$ line. After that, it worked in a row-following mode to debug parameters of the PID controller both on the asphalted surface and paddy fields. The ground speeds were controlled to $0.3 \mathrm{~m} / \mathrm{s}$ (low speed), $0.7 \mathrm{~m} / \mathrm{s}$ (middle speed), and $1.2 \mathrm{~m} / \mathrm{s}$ (high speed), correspondingly. The rice-transplanter was steered automatically in the paddy field to adjust the parameters of the controller. Crosstrack error (XTE) (Zhang et al. (2012)), distance between the currently measured GPS position and the desired track, was used to evaluate the system performance.

The global Kalman filter and the local one alternated with frequency of 1:4. Figure 4 shows a positioning estimation of go-turn-back. Sparse positioning data were supplemented successfully in the row-following mode, while those points deviated from the GPS measured in the U-turning mode. This appearance might be caused by two reasons. One was that Kalman fitler was built on linear 
presupposition that it worked better in the row-following mode than in U-turning mode. It was shown that the positioning lagged behind GPS measurement from the start of U-turn and kept deviation in this stage. The other was that local filter relied only on the heading angles from the gyroscope. Figure 4(b) shows the results of interpolated points between any two real GPS-measured points. As shown in lower part of figure 4(b), the estimated position might deviate notably when the heading angles measured by the gyroscope and the heading direction measured by the GPS were in opposite directions. The precision of the gyroscope was measured by accumulating products of angular velocity and time interval, which resulted in being waved between $-2^{\circ}$ and $2^{\circ}$ when lasting for 10 minutes. Heading angle was reset to zero in every starting of the row-following mode after U-turn to prevent the accumulated deviation of gyroscope.

The target point distance, $L_{T}$, could be set in quite a free way. To evaluate the effect of $L_{T}$ value on the system performance, a series of test trials was carried out by changing $L_{T}$ ranged from $0.4 \mathrm{~m}$ to $1.6 \mathrm{~m}$ on different vehicle speeds. As presented in table 1, difference of RMS

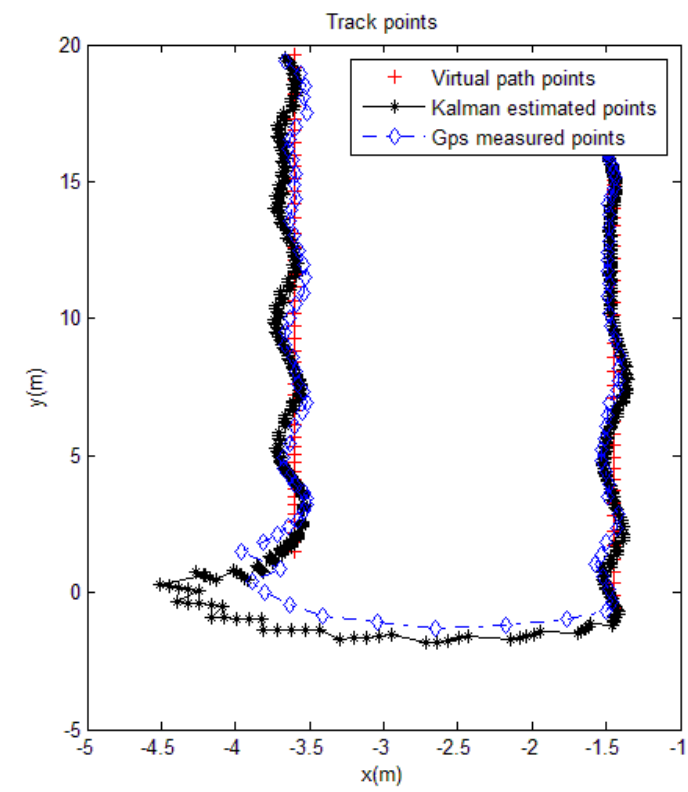

(a)

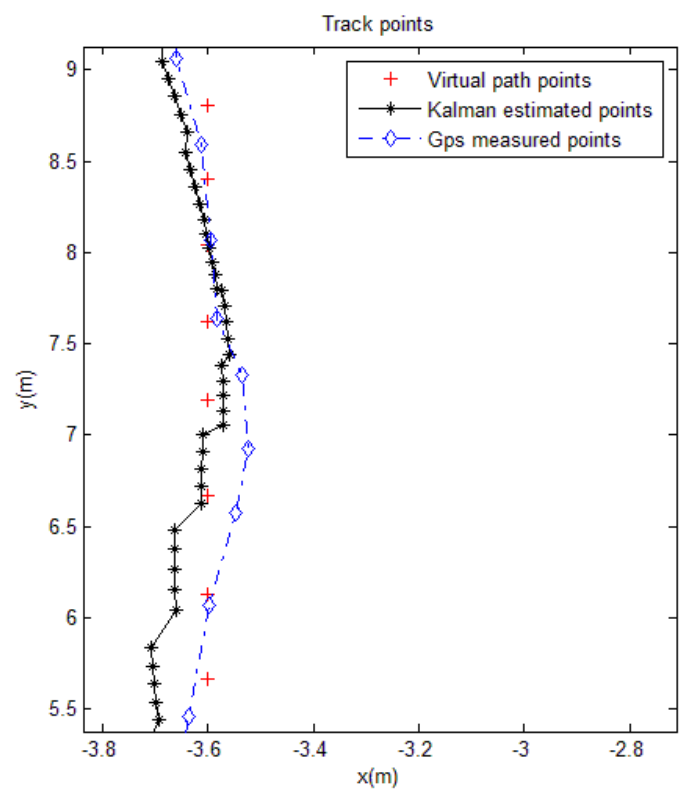

(b)

Figure 4. Positioning estimation by two Kalman filters; (a) track of go-turn-back, (b) comparison of Kalman filter estimation and GPS measurements.

Table 1. RMS errors and the difference of max-min offset with different $L_{T}$ setting

\begin{tabular}{|c|c|c|c|c|c|c|}
\hline \multirow{3}{*}{$L_{T}(\mathrm{~m})$} & \multicolumn{2}{|c|}{$v=0.3 \mathrm{~m} / \mathrm{s}$} & \multicolumn{2}{|c|}{$v=0.7 \mathrm{~m} / \mathrm{s}$} & \multicolumn{2}{|c|}{$v=1.2 \mathrm{~m} / \mathrm{s}$} \\
\hline & \multicolumn{2}{|c|}{$K_{p}=K_{d}=0.5, K_{i}=0$} & \multicolumn{2}{|c|}{$K_{p}=K_{d}=0.5, K_{i}=0$} & \multicolumn{2}{|c|}{$K_{p}=K_{d}=0.2, K_{i}=0$} \\
\hline & $\begin{array}{l}\text { Offset RMS } \\
\text { (m) }\end{array}$ & $\begin{array}{l}\text { Max-min } \\
\text { (m) }\end{array}$ & $\begin{array}{l}\text { Offset RMS } \\
\text { (m) }\end{array}$ & $\begin{array}{l}\text { Max-min } \\
(\mathrm{m})\end{array}$ & $\begin{array}{l}\text { Offset RMS } \\
(\mathrm{m})\end{array}$ & $\begin{array}{c}\text { Max-min } \\
(\mathrm{m})\end{array}$ \\
\hline 0.4 & 0.0538 & 0.2739 & 0.0805 & 0.3803 & 0.0675 & 0.2884 \\
\hline 0.6 & 0.0450 & 0.2246 & 0.0437 & 0.2058 & 0.0387 & 0.1861 \\
\hline 0.8 & 0.0325 & 0.1412 & 0.0423 & 0.1980 & 0.0708 & 0.2341 \\
\hline 0.9 & 0.0383 & 0.1568 & 0.0843 & 0.4811 & 0.0914 & 0.4071 \\
\hline 1.0 & 0.0313 & 0.1373 & 0.0414 & 0.2033 & 0.0838 & 0.2916 \\
\hline 1.1 & 0.0308 & 0.1406 & 0.0367 & 0.1844 & 0.0619 & 0.2316 \\
\hline 1.2 & 0.0377 & 0.1799 & 0.0529 & 0.2290 & 0.1301 & 0.4954 \\
\hline 1.4 & 0.0418 & 0.1964 & 0.0610 & 0.2464 & 0.0837 & 0.3033 \\
\hline 1.6 & 0.0429 & 0.2037 & 0.0494 & 0.2215 & 0.0516 & 0.2241 \\
\hline
\end{tabular}


errors among different $L_{T}$ settings was relatively small when running in low or middle speeds. The minimum RMS error was $3.13 \mathrm{~cm}$ when it ran with speed of $0.3 \mathrm{~m} / \mathrm{s}$, $K_{p}=K_{d}=0.5$, and target point distance of $1.1 \mathrm{~m}$. The RMS error increased when running in high speed.

The controller parameters should be adjusted with different vehicle speeds. The parameter $K_{i}$ was always ignored when driving in low or middle speeds, that is, a PD controller should be worked well as shown in figure 5 (a) and (b). It showed that the PID parameters, $K_{p}$ and $K_{d}$, should be decreased as the running speed increased. However, in the highest speed, the offset was enlarged and the transplanter ran off its track for several meters continuously as shown in figure 5 (c). $K_{i}$ parameter turned out to be helpful to improve long time offtrack when $K_{i}$ was set to 0.2 (Figure $5(d)$ ).

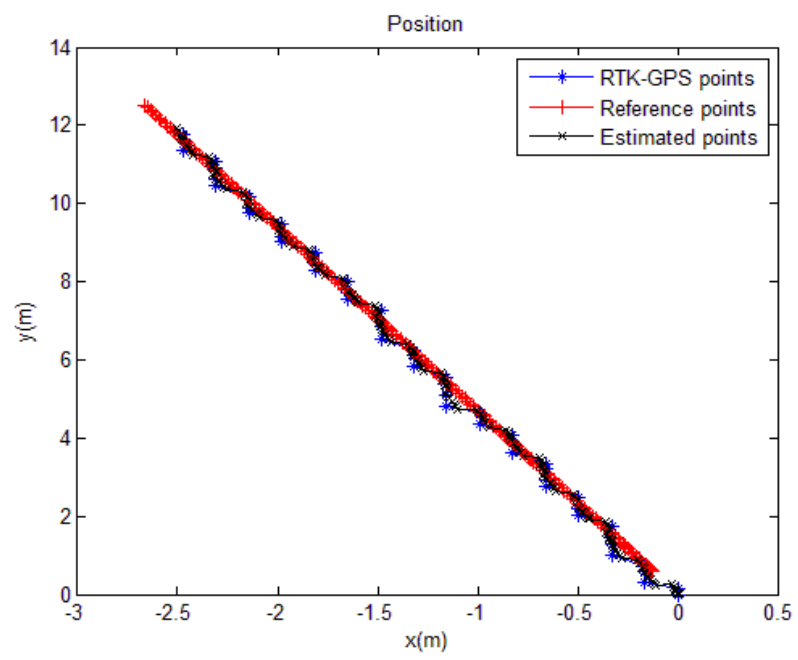

(a) $v=0.3 \mathrm{~m} / \mathrm{s}, K_{p}=K_{d}=0.5, K_{i}=0, L_{T}=1.1 \mathrm{~m}$

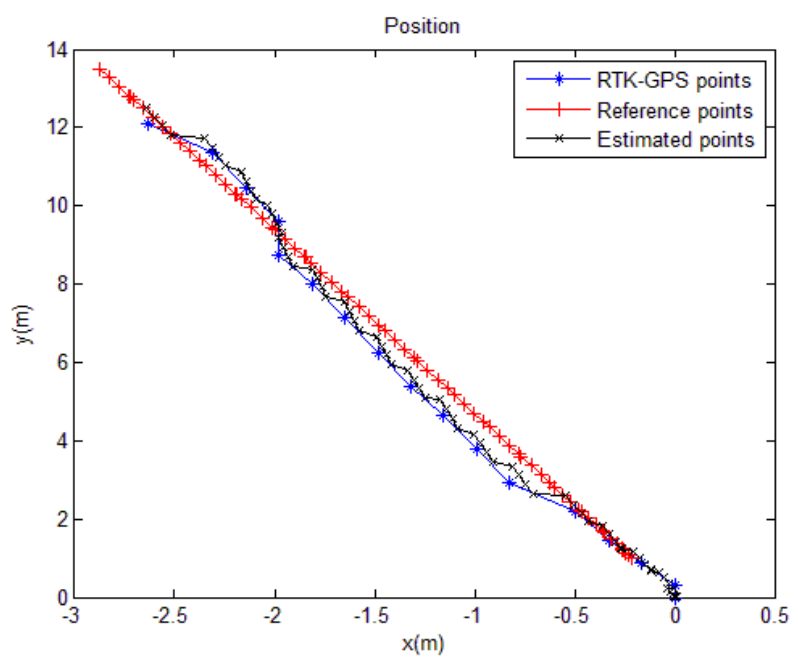

(c) $v=1.2 \mathrm{~m} / \mathrm{s}, K_{p}=K_{d}=0.2, K_{i}=0, L_{T}=1.0 \mathrm{~m}$
To make the machine move back to its track as fast as possible, experiments were done by changing stationary steering angles from $5^{\circ}$ to $20^{\circ}$ in the paddy field. Results showed that the machine moved smoothly along the reference line when the stationary steering angle was set from $6^{\circ}$ to $8^{\circ}$. The machine moved back quickly when larger angles were set, but it would move in a zigzag direction with an amplitude greater than $20 \mathrm{~cm}$ for long distances. Figure 6(a) illustrated a typical path with this control method in a paddy field. The machine started from northwest corner, and then moved to east with a speed about $0.6 \mathrm{~m} / \mathrm{s}$. It followed reference lines with small offset except some dept ditch hides under liquid soil that the machine might slide to the bottom of the groove. It made a U-turning at the end of rows and moved to the next rows quickly.

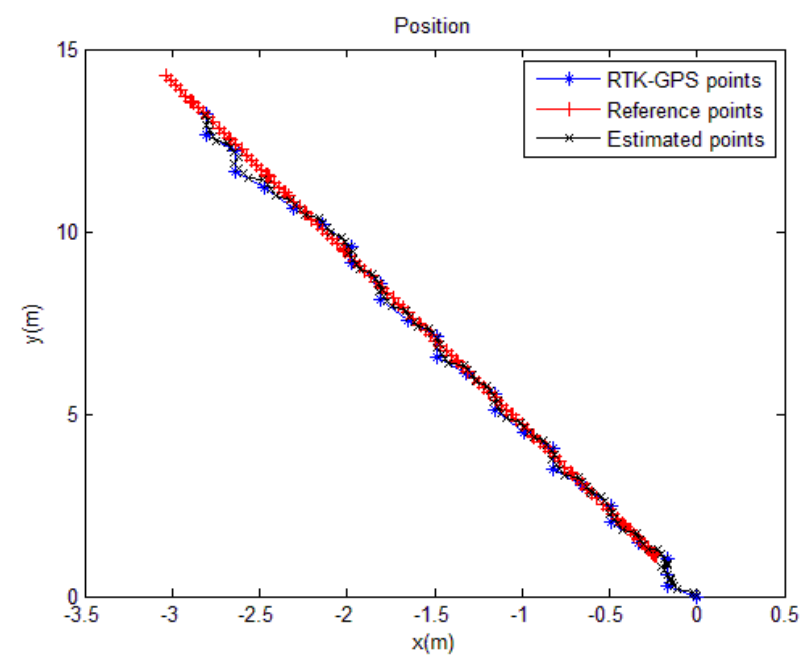

(b) $v=0.7 \mathrm{~m} / \mathrm{s}, K_{p}=K_{d}=0.5, K_{i}=0, L_{T}=1.1 \mathrm{~m}$

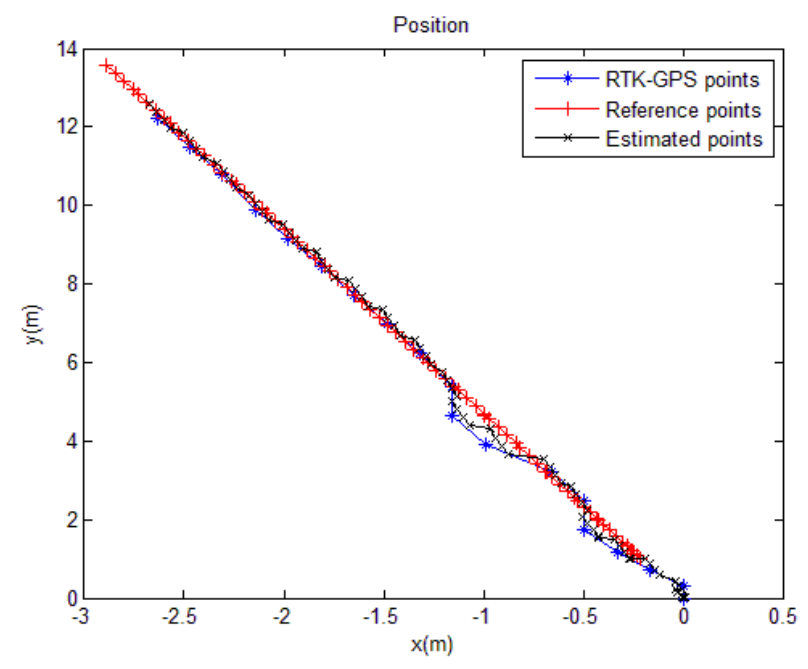

(d) $v=1.2 \mathrm{~m} / \mathrm{s}, K_{p}=K_{d}=0.2, K_{i}=0.2, L_{T}=1.0 \mathrm{~m}$

Figure 5. Path trajectory of the transplanter on different vehicle speeds. 


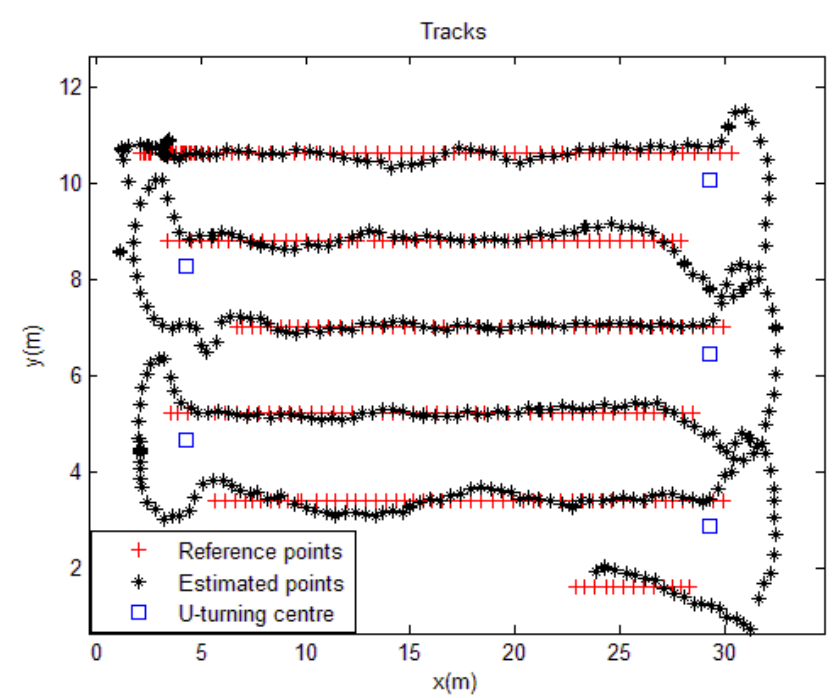

(a)

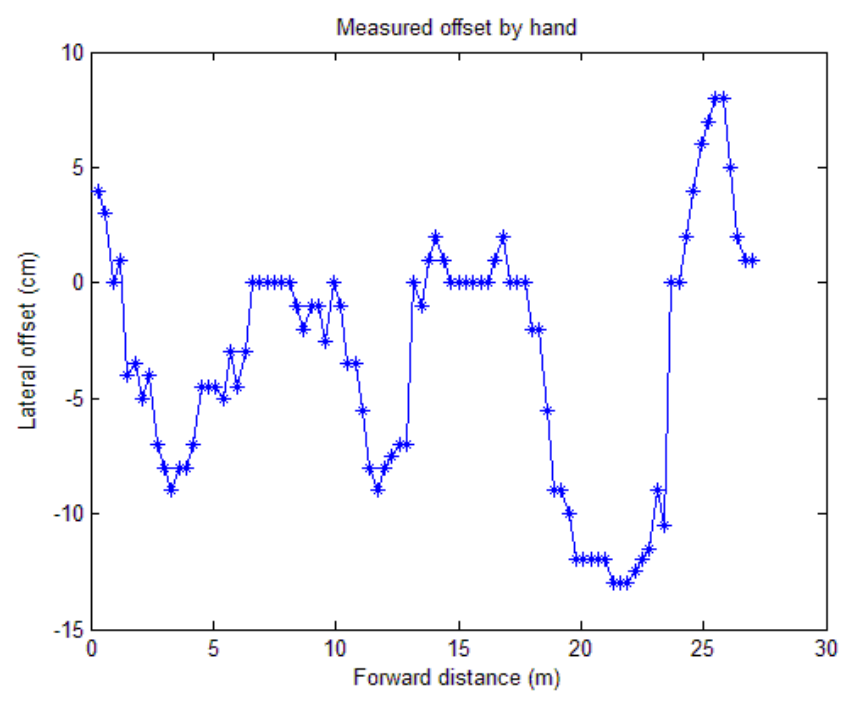

(c)

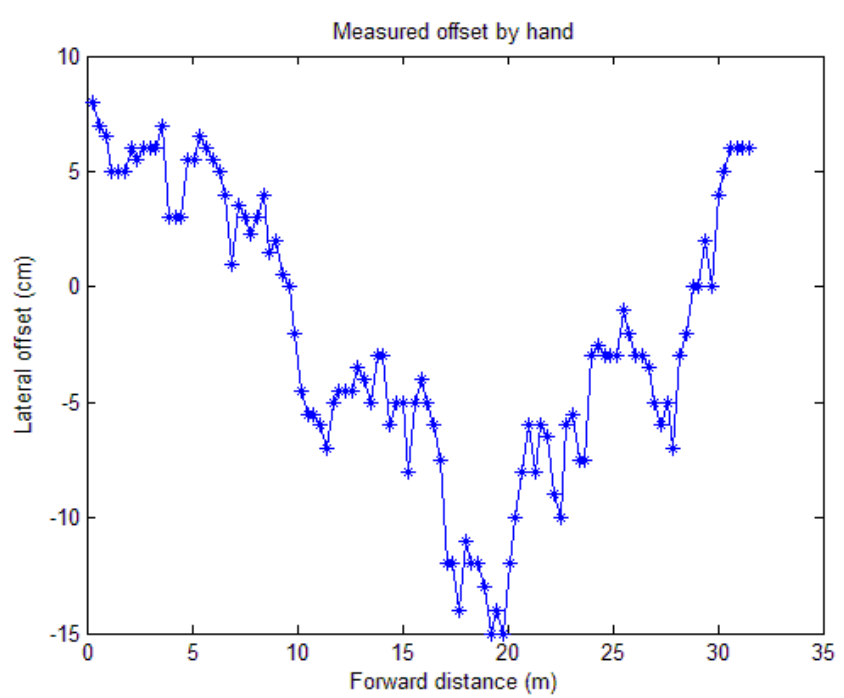

(b)

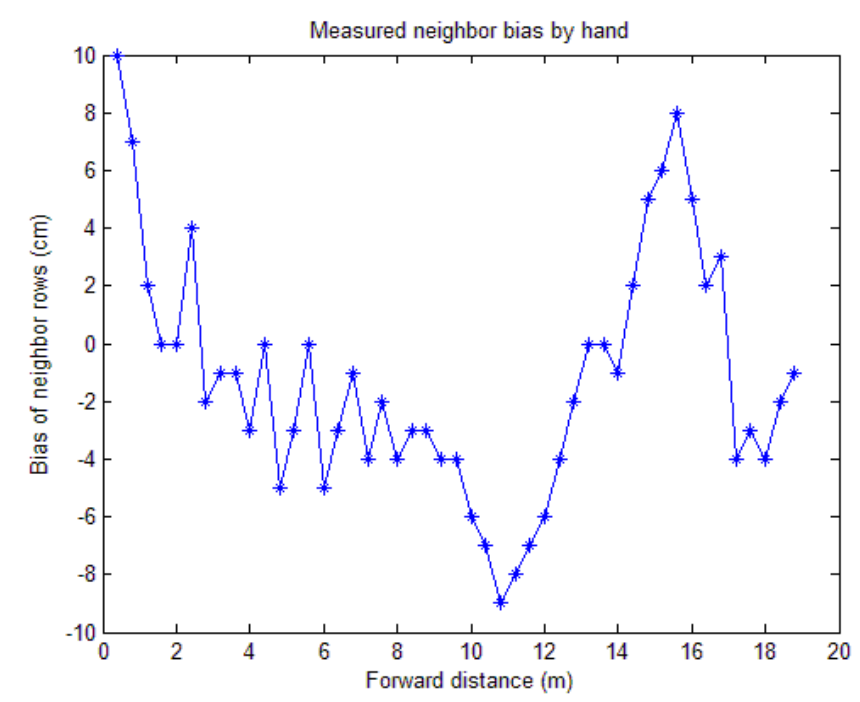

(d)

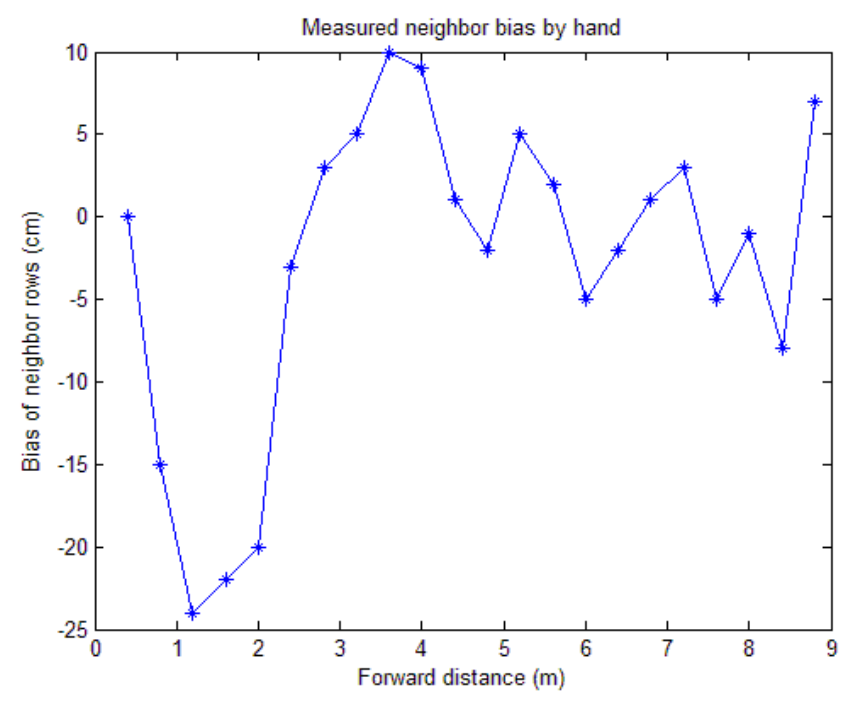

(e)

Figure 6. (a) path recorded by the RTK-GPS in a paddy field; (b) and (c) lateral offset of rice seedlings; (d) and (e) distance deviations of two neighbors rows. 
With respect to a tensed rope over two rice seedlings, the offset of each single seedling was measured, which was the distance between two neighbor seedlings representing two rows. Figure $6(\mathrm{~b})$ and (c) showed their offsets, and figure 6(d) and (e) showed their distance deviation compared to the standard row distance of $30 \mathrm{~cm}$. The RMS values of offset were $6.02 \mathrm{~cm}$ and $5.3 \mathrm{~cm}$, respectively.

\section{Conclusions}

A prototype of guidance system for transplanter was developed, which consisted of three parts: guidance sensors, embedded computers, and electro-steering wheel. The position-velocity (PV) model constructed both for the global Kalman filter and local one showed helpful results to interpolate positioning data in case of sparse GPS data. A target angle-based PID controller plus stationary steering angle controller was developed to steer the transplanter following a reference line accurately. Furthermore, a control method of U-turning was built. Experiments of row-following and U-turning showed that the target point distance could be set in a range of 0.6 $\mathrm{m}$ to $1.6 \mathrm{~m}$, and all PID controller parameters should be set to 0.2 when runing in a high speed. Results showed it could replace human drivers to steer a rice-transplanter. However, due to adverse surface condition in paddy fields such as ditch and slope, the system should be able to control the vehicle speed in order to prevent it from deviating too much for the further works.

\section{Conflict of Interest}

No potential conflict of interest to this article was reported.

\section{Acknowledgments}

The authors wish to express their sincere thanks for the financial support from the Science Foundation of NingBo (Projects 2010A610140 and Projects 2011A610154), Smart Agricultural Machine project of Ningbo Agricultural Machine Bureau (2013), Agriculture R\&D project of Yingzhou (3rd batch, 2012).

\section{References}

Chen, W., B. Xie and Z. Song. 2006. Electro-hydraulic power steering system for tractors. Transactions of the CSAE 22(10):122-125 (in Chinese).

Guo, L., Y. He, Q. Zhang and S. Han. 2002. Real-time tractor position estimation system using a kalman filter. Journal of CSAE 18(5):96-101.

Han, X. Z., H. J. Kim, H. C. Moon, H. J. Woo, J. H. Kim and Y. J. Kim. 2013. Development of a Path Generation and Tracking Algorithm for a Korean Auto-guidance Tillage Tractor. Journal of Biosystems Engineering 38(1):1-8.

Hu, L., X. Luo and Z. Zhao. 2009. Design of electronic control device and control algorithm for rice transplanter. Transactions of the CSAE 25(4):118-122 (in Chinese).

Kise, M., N. NOGUCHI, K. Ishii and H. Terao. 2002. The Development of the Autonomous Tractor with Steering Controller Applied by Optimal Control. Proceedings of the Conference in Automation Technology for Off-Road Equipment, Chicago, IL, USA, July 26-27, 2002:367-373.

Luo, X., Z. Zhang and Z. Zhao. 2009. Design of DGPS navigation control system for Dongfanghong X-804 tractor. Transactions of the CSAE 25(11):139-145.

Mizushima, A., K. Ishii and N. Noguchi. 2011. Development of a low-cost attitude sensor for agricultural vehicles. Computers and Electronics in Agriculture 76:198-204. Noguchi, N., J.F. Reid and Q. Zhang. 2001. Development of Robot Tractor Based on RTK-GPS and Gyroscope. ASAE Annual International Meeting, Sacramento, CA, USA, July 30-August 1, 2001, Paper Number: 01-1195.

Shin, B. S., S. H. Kim and J. U. Park. 2002. Autonomous Agricultural Vehicle Using Overhead Guide. Proceedings of the Conference in Automation Technology for Off-Road Equipment, Chicago, IL, USA, July 26-27, 2002:261-269.

Subramanian, V. and T. F. Burks. 2006. Sensor Fusion Using Fuzzy Kalman Filter for Autonomous Vehicle Guidance. ASABE Annual International Meeting, Portland, OR, USA, July 9 - 12, 2006, Paper Number: 063031.

Tillett, N.D., T. Hague and J. A. Marchant. 1998. A Robotic System for Plant-Scale Husbandry. J. Agric. Engng Res. 69:169-178.

Yekutieli, O. and F. G. Pegna. 2002. Automatic Guidance of 
a Tractor in a Vineyard. Proceedings of the Conference in Automation Technology for Off-Road Equipment, Chicago, IL, USA, July 26-27, 2002:252-260.

Zhang, F., Y. Ying, Q. Zhang and B. Shin. 2006. Visionbased Position System for Agricultural Vehicle Using Extended Kalman Filter. ASAE Annual International Meeting, Portland, Oregon, July 9 - 12, 2006, Paper No.
061157.

Zhang, F., X. Feng and Y. Li. 2012. A Low-Cost Positioning System for Parallel Tracking Applications of Agricultural Vehicles by Using Kalman Filter. IFIP Advances in Information and Communication Technology, 2012, Volume 368, Computer and Computing Technologies in Agriculture V: 461-470. 